\title{
Maturational Changes in Airway Smooth Muscle Structure-Function Relationships
}

\author{
HOWARD B. PANITCH, KIRAN S. DEORAS, MARLA R. WOLFSON, AND THOMAS H. SHAFFER \\ Departments of Pediatrics and Physiology, St. Christopher's Hospital for Children, Temple University School of \\ Medicine, Philadelphia, Pennsylvania 19134-1095
}

\begin{abstract}
Airways become less compliant with age. When examined at either extreme of the developmental spectrum, airway smooth muscle (ASM) undergoes changes that parallel the trachea: both passive and active stress increase from preterm to adult. To determine how ASM changes throughout maturation, trachealis muscles from sheep airways of five age groups (group 1, $<110$ d gestation; group 2, 110-124 d gestation; group 3, 125-140 d gestation; group 4, newborn; and group 5, adult) were separated from their cartilaginous supports and cleaned of their mucosa and serosa. The length at which active stress was optimal was determined and passive and active stress were measured. Concentration-effect curves for acetylcholine (ACh) and $\mathrm{KCl}$ were performed at the length at which active stress was optimal. Morphometric analysis of the muscle was performed by computerized image analysis. At the length at which active stress was optimal, both passive and active stress increased with maturation $(p<0.001)$. Concentration-effect curves for both $\mathrm{ACh}$ and $\mathrm{KCl}$ also showed a significant increase in active stress as a function of dose and of age $(p<0.002)$, and the $\mathrm{ED}_{50}$ for $\mathrm{ACh}$ decreased with maturation $(p<0.005)$. Although muscle length, thickness, and area increased with age $(p<0.005)$, the ratio of contractile to connective tissue within the muscle bundle remained constant throughout maturation. These data demonstrate that ASM undergoes a progressive increase in contractility and sensitivity to $\mathrm{ACh}$ throughout maturation. The inability of immature ASM to generate as much force as adult ASM may in part explain why preterm infants who require positive-pressure ventilation are at risk to sustain structural central airway injury. (Pediatr Res 31: 151-156, 1992)
\end{abstract}

\section{Abbreviations}

KBS, Krebs buffer solution

$L_{o}$, length of muscle at which active stress is optimal

A, cross-sectional area

ACh, acetylcholine

ANOVA, analysis of variance

$\mathrm{C}_{\mathrm{s}}$, specific compliance of the trachealis muscle

Immature airways are compliant structures (1-3). Studies investigating changes in airway mechanics as a function of maturation have shown that compliance decreases progressively from fetus to adult $(1,2,4)$.

Received January 8, 1991; accepted September 20, 1991.

Correspondence and reprint requests: Howard B. Panitch, M.D., Section of Pulmonology and Allergy, St. Christopher's Hospital for Children, Erie Ave. at Front St. Philadelphia, PA 19134-1095.

Supported in part by Biomedical Research Support Grant SO7 RR05417 from the Division of Research Resources, National Institute of Health.
Airway smooth muscle stimulation can decrease airway compliance independently of age $(3,5-7)$. Recently, differences in airway smooth muscle contractility and passive tension generation have been described between adults and preterms that parallel compliance changes in the trachea as a whole (8). Both active and passive tension of the trachealis itself are 2.5 times greater in the adult than in the preterm airway. Similar trends have been recognized in other smooth muscle systems (9-11). Morphologic and/or biochemical changes responsible for these alterations, however, remain poorly understood.

There is a clear change in force generation between the extremes of developmental age. Whether the increase in tracheal muscle tone is responsible for the decrease in tracheal compliance, however, is not known. Nor is it known when during development these changes occur or whether the trachealis undergoes age-related structural changes in its contractile or connective tissue components.

The purpose of the present study, therefore, was to examine trachealis force generation and morphometry over the entire range of development to determine the effect of maturation, and to relate maturational aspects of force development to changes in airway compliance.

\section{MATERIALS AND METHODS}

Sheep ranging from $102 \mathrm{~d}$ postconception to adulthood were separated by age. Preterm animals were divided into three groups: group 1, <110 d; group 2, 110-124 d; and group 3, 125-140 d postconception, with normal gestation being $147 \pm 3 \mathrm{~d}$. Newborn animals (1-7 d) and adults (2-6 y) composed groups 4 and 5, respectively.

Newborn lambs were sedated with nembutal $20 \mathrm{mg} / \mathrm{kg}$ intraperitoneally. Adult pregnant ewes were sedated with ketamine $\mathrm{HCl} 500 \mathrm{mg}$ and received epidural anesthesia with $0.75 \%$ bupivicaine $0.5-1.0 \mathrm{mg} / \mathrm{kg}$ (Marcaine; Winthrop Pharmaceuticals, New York, NY). Subsequently, preterm sheep were delivered by uterotomy. All animals were killed by lethal injection of T-61, and tracheal segments from newborn, adult, and preterm sheep were excised immediately after death. All segments were obtained from the rostral third of the extrathoracic trachea to control for any possible regional differences in force generation. The segments were stored in $\mathrm{KBS}$ (composition in $\mathrm{mM}: 120 \mathrm{NaCl}, 5$ $\mathrm{KCl}, 2.5 \mathrm{CaCl}_{2}, 1.2 \mathrm{MgCl}_{2}, 11.5$ glucose, $22 \mathrm{NaHCO}_{3}, 1.2$ $\mathrm{NaH}_{2} \mathrm{PO}_{4}$ ), pH $7.40 \pm 0.05$, at $13^{\circ} \mathrm{C}$. This protocol was approved by the Institutional Animal Care and Use Committee of Temple University.

Within $24 \mathrm{~h}$ of death, the tracheal segment was placed in a Sylgard-lined petri dish (Dow Corning, Midland, MI) filled with aerated KBS at room temperature. Using a dissecting microscope, the trachealis was carefully separated from its cartilaginous attachments, and both the serosal adventitia and the luminal epithelium and submucosa were removed by sharp dissection. Muscle fibers could be clearly visualized, and segments were cut parallel to their fiber orientation into strips measuring $1-2 \times 5$ 
$\mathrm{mm}$ (preterm strips), 1-2 $\times 10 \mathrm{~mm}$ (newborn strips), or $2 \times 15-$ $20 \mathrm{~mm}$ (adult strips). When more than one strip was studied from an airway, results were averaged and reported as a single result for that airway. Preliminary studies demonstrated no significant decrement in force generation resulting from overnight storage in either the preterm or adult strips.

Each muscle strip was suspended vertically in a bath filled with warmed $\left(37^{\circ} \mathrm{C}\right) \mathrm{KBS}$, through which a mixture of $95 \% \mathrm{O}_{2} / 5 \%$ $\mathrm{CO}_{2}$ was continuously bubbled. One end of each strip was attached to a fixed rod. The other was attached to a force transducer (Grass FTO3C) by means of a wire whose compliance was negligible over the range of forces measured. The force transducer was attached to a screw micrometer to allow for lengthening of the strip. The muscle strips were equilibrated under zero load for $60-90 \mathrm{~min}$ before the study. Allowing the strips to equilibrate under $0.5-$ to $1.0-\mathrm{g}$ loads did not alter results. Reproducible response to a fixed dose of agonist several times throughout the experiment assured against decrement in force generation throughout the length of the experiment. Strips were considered viable if subsequent responses were within $15 \%$ of the original maximal response.

Determination of optimum passive and active forces. The mean age, $L_{0}$, and $A$ for the muscle strips studied, as well as the number of airways and muscle strips studied in each group, are presented in Table 1.

Force was recorded on a multichannel recorder (7P1; Grass Instrument Co., Quincy, MA). All strips were stretched and then stimulated with $10^{-5} \mathrm{M} \mathrm{ACh}$. As previously described (8), the strips were washed with fresh KBS until they returned to their baseline passive force, after which the stretch-stimulation sequence was repeated. $L_{o}$ was determined for each strip, and the passive force was noted at $\mathrm{L}_{\mathrm{o}}$.

Concentration-effect studies. All studies were performed with the strips set at $\mathrm{L}_{\mathrm{o}}$. Noncumulative concentration-effect curves for ACh were obtained on four airways (four strips) in group 1, 16 airways (19 strips) in group 2, five airways (five strips) in group 3 , seven airways (14 strips) in group 4, and eight airways (eight strips) in group 5 . Concentrations of $\mathrm{ACh}$ ranged from $10^{-8}$ to $10^{-4} \mathrm{M}$. Doses greater than $10^{-4} \mathrm{M}$ were not used because force would not return to baseline after the drug was washed from the strips at higher concentrations.

Noncumulative concentration-effect curves for $\mathrm{KCl}$ were obtained on four airways (four strips) in group 1, 13 airways (16 strips) in group 2, four airways (four strips) in group 3, five airways (eight strips) in group 4, and five airways (five strips) in group 5. Concentrations of KCL ranged from 5 to $100 \mathrm{mM}$. All concentrations of KCL $>5 \mathrm{mM}$ were achieved by replacing part of the $\mathrm{NaCl}$ in the buffer with an isosmotic equivalent of $\mathrm{KCl}$.

At the end of the experiment, all strips were measured at $\mathrm{L}_{\text {o }}$ with a calibrated eyepiece micrometer. The muscle strips were blotted on paper toweling, and the wet weight of each strip was determined. Passive force $(\mathrm{g})$ was normalized for $\mathrm{A}$ to yield stress $\left(\mathrm{g} / \mathrm{cm}^{2}\right)$. The A was calculated using the relationship $A=M / \rho$ $\mathrm{L}$, where $\mathrm{M}$ is mass $(\mathrm{g}), \mathrm{L}$ is length of the muscle $(\mathrm{cm})$, and $\rho$ is muscle density $\left(\mathrm{g} / \mathrm{cm}^{3}\right)$, assuming the density of smooth muscle as $1.05 \mathrm{~g} / \mathrm{cm}^{3}(12)$. Active force was first normalized for $\mathrm{A}$, then corrected for the percentage of muscle within the strip as determined morphometrically (see below).
Morphometric studies. Tracheal segments from each group (group 1, $n=5$; group 2, $n=7$; group $3, n=5$; group 4, $n=8$; and group $5, n=3$ ) were obtained from the area extending between $3 \mathrm{~mm}$ below the cricoid and $20 \mathrm{~mm}$ above the carina in each animal to avoid differences secondary to regional variation. The segments were fixed in $2 \%$ glutaraldehyde, and routine histologic techniques were used to process and embed the tissues in paraffin (13). Seven- $\mu \mathrm{m}$ cross-sections were prepared for light microscopy and stained with Milligan's Trichrome, which provided a strong contrast between muscle fibers and connective tissue.

As previously described (14), a computerized image analysis system was used to quantitate muscle dimensions. Briefly, the histologic slides prepared above were digitized and presented on a video monitor coupled to a touch screen. The length, thickness, and area of the tracheal muscle bundle were determined by outlining the respective parameters on the touch screen. The muscle fibers within the muscle bundle were outlined densitometrically, according to the differences in staining intensity between the muscle fibers and surrounding tissue, and their dimensions were computed. The proportion of muscle fibers in the muscle bundle was calculated from the above data. Multiple (greater than five) sections were analyzed per airway, and the measurements were averaged.

Data analysis. Passive and active stress at $\mathrm{L}_{\mathrm{o}}$ were compared and analyzed by a one-way ANOVA to evaluate tension as a function of age. The compliance (C) of each muscle strip between $80-100 \% \mathrm{~L}_{\mathrm{o}}$ was calculated using the relationship $\mathrm{C}=\Delta \mathrm{L} / \Delta$ stress, where $\Delta \mathrm{L}$ is the change in length of the muscle $(\mathrm{cm})$ and $\Delta$ stress is the change in normalized passive force $\left(\mathrm{g} / \mathrm{cm}^{2}\right)$. The value obtained was corrected for the length of the strip at $\mathrm{L}_{\circ}(\mathrm{cm})$ to yield $\mathrm{C}_{\mathrm{s}}$. The $\mathrm{C}_{\mathrm{s}}$ for each group was compared and analyzed by a one-way ANOVA.

The contractile responses of the muscle strips at $\mathrm{L}_{\mathrm{o}}$ to each dose of agonist were plotted as a function of agonist concentration. The response to $\mathrm{ACh}$ for each airway was also normalized to its maximal response, and the $\mathrm{ED}_{50}$, the dose required to achieve a one-half maximal response, was graphically calculated. Active stress at each concentration of agonist was compared by a two-way ANOVA to evaluate differences as a function of dose and of age. The assumption was made that previous exposure to the agonist did not affect subsequent measurements to allow for this analysis. The $\mathrm{ED}_{50}$ of $\mathrm{ACh}$ for each group was compared and analyzed by one-way ANOVA. Differences in muscle dimensions among the five groups were analyzed by one-way ANOVA.

Statistical significance was accepted at the $p<0.05$ level. All values are denoted as mean \pm SEM. Tukey or Neuman-Keuls post-hoc testing was performed where significant differences were found.

\section{RESULTS}

Optimum passive and active stress. The length of the muscle strips at $\mathrm{L}_{\mathrm{o}}$ and $\mathrm{A}$ for the preterm and newborn groups were similar, but differed from the adult group (Table 1). Passive and active stress at $L_{o}$ for each group are shown (Fig. 1). Passive stress values increased as a function of age $(p<0.001)$; Tukey post-

Table 1. Characteristics of tissues used to determine passive and active tensions at $L_{0}{ }^{*}$

\begin{tabular}{|c|c|c|c|c|c|}
\hline & \multicolumn{5}{|c|}{ Group } \\
\hline & 1 & 2 & 3 & 4 & 5 \\
\hline Age (d) & $105 \pm 1$ & $114 \pm 0.4$ & $128 \pm 1$ & $151 \pm 0.7$ & $4.1 \pm 1.4 y$ \\
\hline$n$ (airways) & 8 & 25 & 5 & 10 & 16 \\
\hline$n$ (strips) & 9 & 30 & 5 & 15 & 24 \\
\hline $\mathrm{L}_{\mathrm{o}}(\mathrm{mm})$ & $4.9 \pm 0.7$ & $5.7 \pm 0.2$ & $6.4 \pm 0.7$ & $7.2 \pm 0.4$ & $14.8 \pm 1.2$ \\
\hline $\mathrm{A} \times 10^{-3}\left(\mathrm{~cm}^{2}\right)$ & $3.3 \pm 0.5$ & $3.9 \pm 0.3$ & $2.8 \pm 0.4$ & $3.4 \pm 0.3$ & $11.8 \pm 1.7$ \\
\hline
\end{tabular}

$*$ Values for age, $\mathrm{L}_{\mathrm{o}}$, and A presented as mean $\pm \mathrm{SEM}$. 


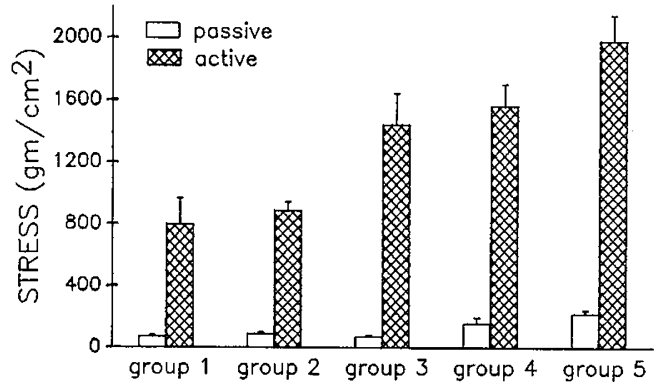

Fig. 1. Passive and active stress of trachealis muscle at $\mathrm{L}_{0}$. All values were normalized for A. Active stress was further normalized for percentage of muscle fibers within the muscle bundle. Both passive and active stress increased with age $(p<0.001)$. Post-hoc analysis demonstrated an increase in passive stress in groups $1-3$ vs group $5(p<0.01)$, whereas there was no difference in group $4 v s$ group 5. Similarly, differences in active stress were noted in group $1 v s$ group $3(p<0.05)$, group $1 v s$ groups 4 and $5(p<0.01)$, group $2 v s$ group $4(p<0.05)$, and group 2 $v s$ group $5(p<0.01)$. Values are mean \pm SEM. See text for ages and numbers of each group.
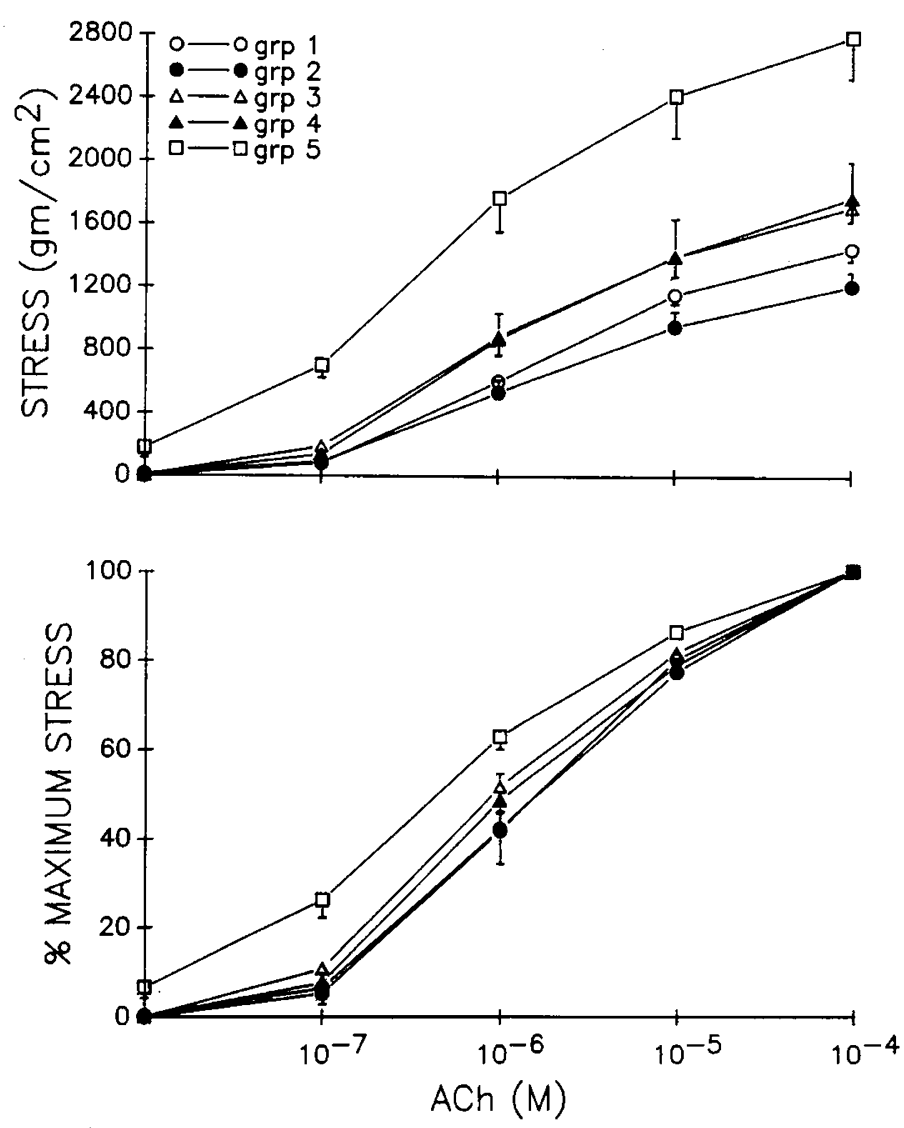

Fig. 2. Concentration-effect curves for ACh. Top panel, active stress values are normalized both to A and percentage of muscle fibers within the muscle bundle. There is a maturational effect of dose and of age on ACh-induced contractions $(p<0.002)$. Values are mean \pm SEM. Bottom panel, active stress values normalized to maximum active stress achieved at each age. These values demonstrate that the $\mathrm{ED}_{50}$ for $\mathrm{ACh}$ decreases with age $(p<0.005)$. The $\mathrm{ED}_{50}\left(\times 10^{-6} \pm \mathrm{SEM}\right)$ for each group was: group 1, $1.76 \pm 0.63$; group 2, $2.12 \pm 0.32$; group 3, $1.00 \pm 0.16$; group $4,1.17 \pm 0.18$; and group $5,0.49 \pm 0.09$.

hoc analysis demonstrated a 3-fold increase in passive stress between preterm and adult groups but no significant difference between newborn and adult groups.

The $\mathrm{C}_{s}$ of the muscle strips decreased with age $(p<0.05)$. Values of $C_{s}\left(\times 10^{-3} \mathrm{~cm}^{2} / g\right.$ stress $\left.\pm S E M\right)$ were: group $1,3.5 \pm$
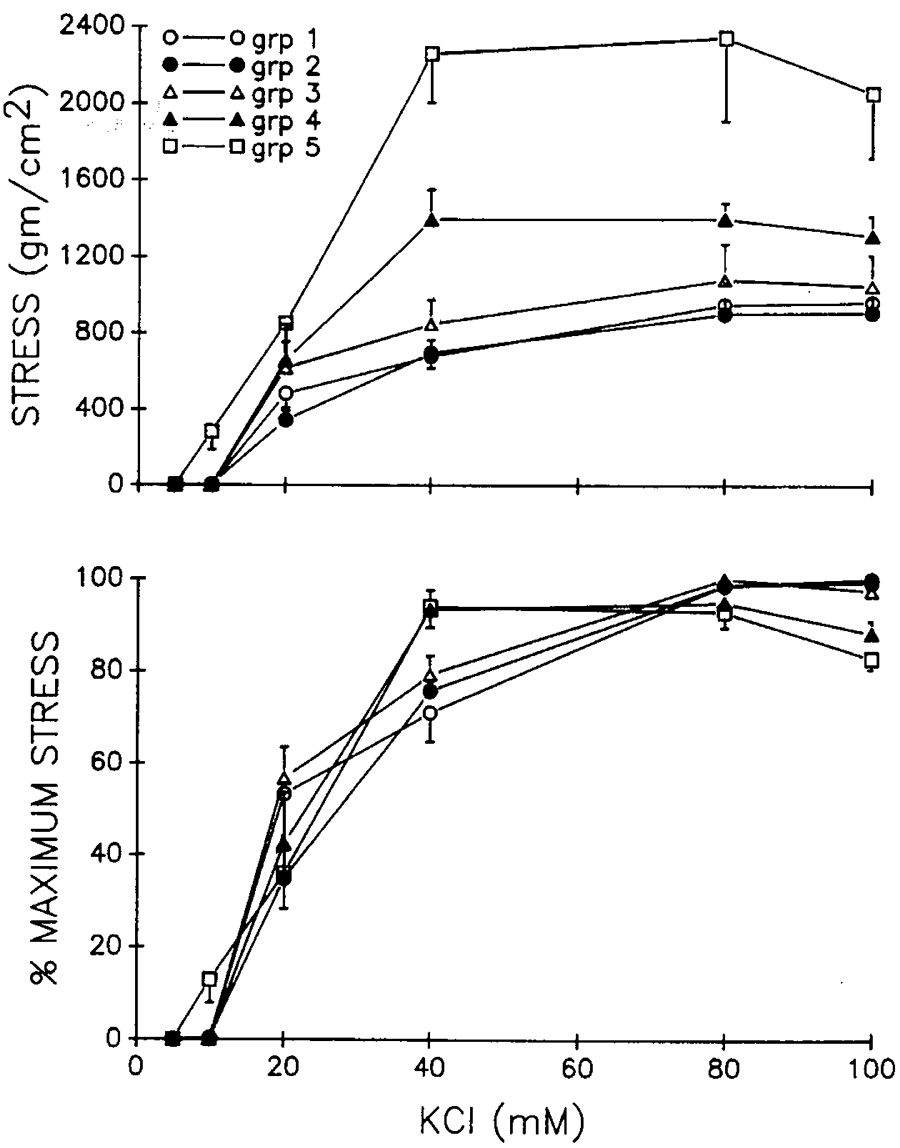

Fig. 3. Concentration-effect curves for $\mathrm{KCl}$. Top panel, Active stress values normalized for $\mathrm{A}$ and percentage of muscle fibers within the muscle bundle. There is a significant effect of both dose and age on $\mathrm{KCl}-$ induced contractions $(p<0.001)$. Values are mean \pm SEM. Bottom panel, Active stress values normalized to maximum $\mathrm{KCl}$-induced active stress values at each age. The dose required to elicit a threshold response is lower in the adult group (group 5) than in any other, and the dose required to achieve maximal stress is lower in the postnatal groups (groups 4 and 5) than in any of the preterm groups.

0.8 ; group 2, $3.5 \pm 0.05$; group 3, $3.2 \pm 0.9$; group 4, $2.6 \pm 0.6$; and group $5,1.5 \pm 0.2$. The adult strips were less compliant than the strips from all the preterm groups $(p<0.05)$, but there was no significant difference in compliance among the preterm or neonatal strips.

Active stress values also increased as a function of age ( $p<$ 0.001 ) (Fig. 1). There was an $11 \%$ increase in active stress between groups 1 and 2, a $63 \%$ increase between groups 2 and 3 , an $8 \%$ increase between groups 3 and 4 , and a $26 \%$ increase between groups 4 and 5 .

Concentration-effect studies. Two-way ANOVA of ACh concentration-effect curves demonstrated a significant increase in force generation as a function of dose and of age $(p<0.002)$ (Fig. 2). The adult group generated significantly greater active stress than any other group $(p<0.01)$ and was able to generate force at a lower concentration $\left(10^{-8} \mathrm{M}\right)$ than any of the less mature groups. When the curves were normalized to maximum stress and the $\mathrm{ED}_{50}$ for each was calculated, a maturational effect was again demonstrated $(p<0.005)$ (Fig. 2).

Two-way ANOVA demonstrated a significant increase in active stress as a function of $\mathrm{KCl}$ dose and of age $(p<0.001)$ (Fig. 3 ). All preterm strips generated increasing active stress as the $\mathrm{KCl}$ concentration was increased, peaking at $80 \mathrm{mM}$. The newborn and adult strips also generated greater active stress at increasing concentrations of $\mathrm{KCl}$, but peaked at $40 \mathrm{mM}$. The adult strips were able to generate force at a lower concentration of $\mathrm{KCl}(10 \mathrm{mM})$ than any other group. 
a)

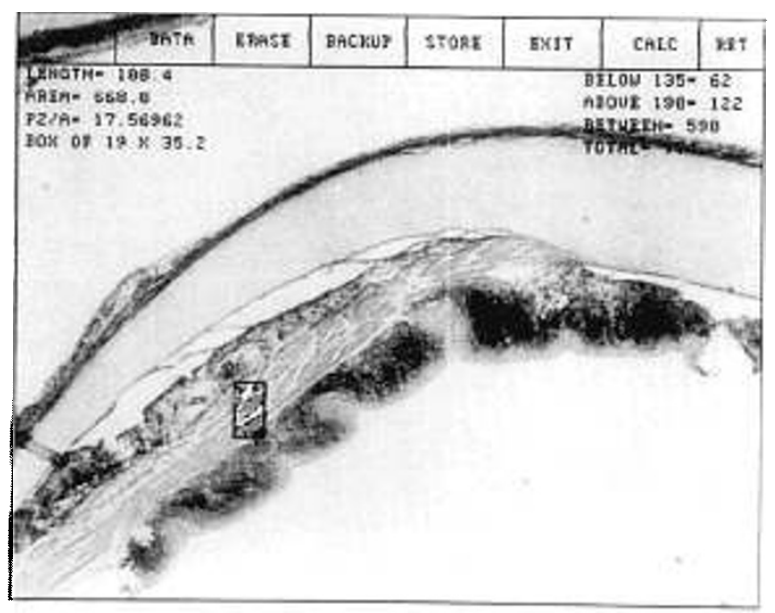

PRETERM

b)

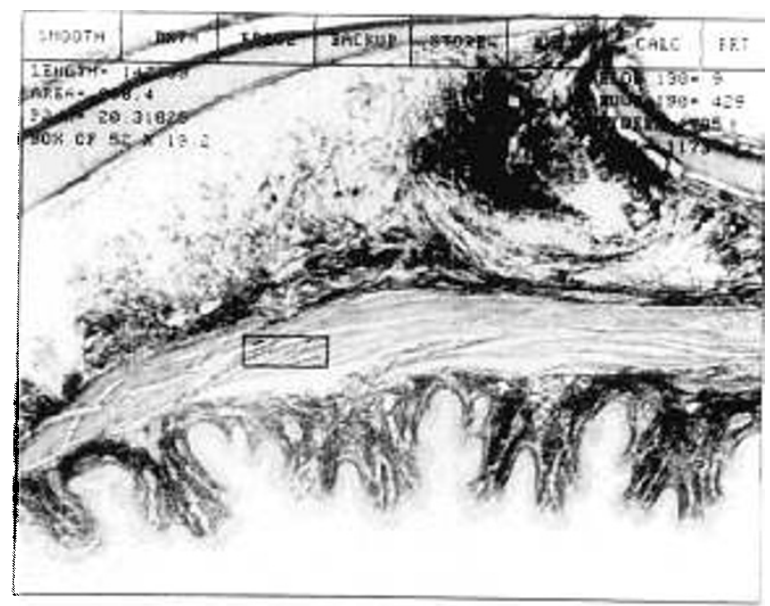

NEWBORN

c)

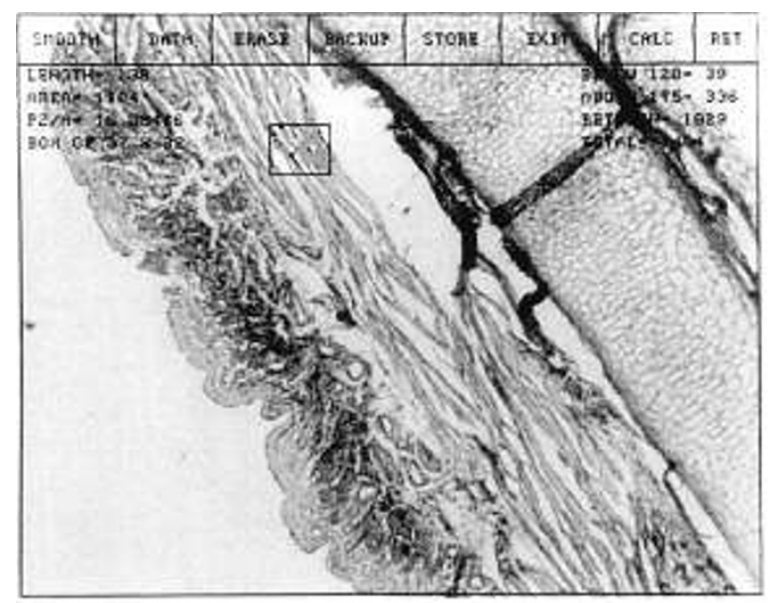

ADULT

Fig. 4. Analysis of muscle/connective tissue ratio by computer densitometry for preterm $(a)$, newborn $(b)$, and adult $(c)$ trachealis muscle. For the above samples, preterm $=76.2 \%$, newborn $=67.8 \%$, and adult $=73.3 \%$. The overall percentage is based on area samples taken along the entire length of muscle (see text). Total $=$ area of box; Between $=$ area of muscle in box; Between/Total $\times 100=\%$ muscle in box (original magnification of each micrograph is $40 \times$ ).
Morphometric studies. Typical histologic sections for preterm, newborn, and adult trachealis strips are shown (Fig. 4). Muscle fibers of the trachealis are distinguished from the surrounding and intervening tissues; the "box" contains densitometrically outlined fibers. The entire muscle length was similarly analyzed.

The length, area, and thickness of the trachealis bundle increased with increasing age $(p<0.005)$ (Table 2). Post-hoc analysis showed that the increases occurred between the preterm and postterm groups, but not between the three preterm groups. The proportion of muscle fibers and intervening connective tissue in the muscle bundle remained constant (Table 2).

\section{DISCUSSION}

This study examined both the functional and structural changes that occur in airway smooth muscle over a wide range of developmental ages. Whereas previous work compared the functional aspects of airway smooth muscle development at either end of the developmental spectrum (preterm versus adult) (8), the present investigation sought to determine what developmental changes in smooth muscle mechanics and structure occur throughout gestation, in the newborn period, and in adulthood.

Because the trachea is composed of both connective tissue and a muscular sheath, examination of the airway as a whole cannot distinguish how its individual component parts change. By removing the airway smooth muscle from its cartilaginous supports, we were able to study developmental changes in the mechanical properties of the trachealis independent of changes in tracheal cartilage.

Results of the present study demonstrate an age-related difference in the resting tone of the trachealis: the passive stress of the isolated trachealis muscle increased 3-fold between the preterm and adult groups. These differences in passive stress cannot be ascribed merely to an increase in muscle mass, because force was normalized for A and the proportion of muscle to connective tissue within the muscle bundle itself remained constant.

Changes in the properties of the intervening ground substance or in the cellular contents of the muscle cells may explain the increase in passive stress noted. Chemical analysis of the proteoglycan intervening skeletal muscle fibers shows differences with development (15), and similar differences may in part be responsible for the observed differences in the passive length-tension characteristics of airway smooth muscle. Other possible causes for the increase in resting tone may include an increase in contractile protein content within each cell $(16,17)$, an increase in the number of crossbridges present, or a difference in geometric conformation of the muscle fibers with age (18).

Passive stress of the trachealis is proportional to its compliance. Although passive length-tension curves from preterm and adult airway smooth muscle demonstrate differences along the entire length-tension curve (8), the present study demonstrates that the compliance of the muscle strip itself about $\mathrm{L}_{\mathrm{o}}$ decreases with age. Moreno et al. (19) have shown that the length of the trachealis at functional residual capacity in mature animals is at $\mathrm{L}_{\mathrm{o}}$. Therefore, a comparison of values of trachealis compliance about $\mathrm{L}_{\mathrm{o}}$ demonstrates a difference in development between the muscle and the airway as a whole.

Several studies have shown that airway compliance decreases with age (1-4). Determinations of tracheal segment compliance over an age range similar to that of the present study demonstrated a 5-fold decrease in tracheal compliance between extremely preterm (67\% gestation) and adult airways (2). The majority of compliance changes occurred prenatally, although there continued to be a gradual but steady decrease in tracheal compliance into adulthood.

Whereas the trachea became less deformable or compliant throughout the preterm period (2), passive stress and compliance of the airway smooth muscle remained constant throughout gestation and increased postnatally. The increase in trachealis passive stress and decrease in trachealis compliance seen with 
Table 2. Comparative morphometry of the trachealis muscle as a function of maturation*

\begin{tabular}{|c|c|c|c|c|c|}
\hline & \multicolumn{5}{|c|}{ Group } \\
\hline & 1 & 2 & 3 & 4 & 5 \\
\hline $\begin{array}{l}\text { Muscle length (mm) } \\
\pm \mathrm{SEM}\end{array}$ & $\begin{array}{l}5.60 \\
0.26\end{array}$ & $\begin{array}{l}5.60 \\
0.27\end{array}$ & $\begin{array}{l}7.24 \\
0.42\end{array}$ & $\begin{array}{l}8.81 \dagger \\
0.51\end{array}$ & $\begin{array}{c}19.69 \dagger \\
0.43\end{array}$ \\
\hline $\begin{array}{l}\text { Muscle area }\left(\mathrm{mm}^{2}\right) \\
\pm \mathrm{SEM}\end{array}$ & $\begin{array}{l}0.61 \\
0.05\end{array}$ & $\begin{array}{l}0.77 \\
0.05\end{array}$ & $\begin{array}{l}1.21 \\
0.06\end{array}$ & $\begin{array}{l}1.93 \dagger \\
0.28\end{array}$ & $\begin{array}{l}4.25 \dagger \\
0.17\end{array}$ \\
\hline $\begin{array}{l}\text { Muscle thickness (mm) } \\
\pm \text { SEM }\end{array}$ & $\begin{array}{l}0.20 \\
0.02\end{array}$ & $\begin{array}{l}0.31 \\
0.02\end{array}$ & $\begin{array}{l}0.35 \\
0.01\end{array}$ & $\begin{array}{l}0.39 \dagger \\
0.04\end{array}$ & $\begin{array}{l}1.88 \dagger \\
0.07\end{array}$ \\
\hline $\begin{array}{l}\% \text { Muscle fibers }\left(\mathrm{mm}^{2}\right) \\
\pm \text { SEM }\end{array}$ & $\begin{array}{r}71.72 \\
1.58\end{array}$ & $\begin{array}{r}72.52 \\
1.98 \\
\end{array}$ & $\begin{array}{r}72.20 \\
2.28 \\
\end{array}$ & $\begin{array}{r}71.53 \\
2.45 \\
\end{array}$ & $\begin{array}{r}73.03 \\
4.48\end{array}$ \\
\hline
\end{tabular}

* All values were derived by morphometric analysis of histologic sections of tracheal rings. Muscle dimensions refer to the plane longitudinal to the fiber orientation. Values for $\%$ muscle fibers were calculated by dividing the area of muscle fibers by total muscle area. The difference (approximately $30 \%$ ) represents the percentage of intervening connective tissue in the muscle bundle.

$\dagger p<0.05$ vs preterms (groups 1,2 , and 3).

maturation could contribute to the observed decrease in tracheal compliance. Other factors, however, must also be responsible for the developmental decrease in compliance, inasmuch as differences in both the magnitude and the rate at which this change occurs exist between the trachealis muscle and the intact trachea.

Tracheal cartilage becomes stiffer or less deformable with age. When the length-tension characteristics of tracheal cartilage were compared between adult and preterm sheep of $118-120 \mathrm{~d}$ gestation (20), the mean slope of the line for tension generated by adult tracheal cartilage was approximately nine times greater than that for preterm cartilage.

Developmental changes in tracheal compliance, then, can result from changes in the stress characteristics of both the muscle and the cartilage. Although the trachea undergoes an absolute increase in both cartilage and muscle mass with development, the proportion of these two elements remains constant across ages (14). Therefore, the age-related difference in tracheal stiffness cannot be explained by a change in the proportion of contractile to connective tissue contents.

At $\mathrm{L}_{\mathrm{o}}$, the active stress generated from a submaximal dose of $\mathrm{ACh}$ increased with age. A small portion of this increase may have resulted from an increase in receptor sensitivity to $\mathrm{ACh}$, because at a dose of $10^{-5} \mathrm{M}$ ACh sensitivity was $10 \%$ greater in group 5 than in group 1. However, active stress increased over the prenatal range (group 1 to group 3) without a significant change in ACh sensitivity. Additionally, active stress increased with age when contractions were achieved by receptor-independent membrane depolarization via $\mathrm{KCl}$. Together, these data suggest that force generation increases throughout maturation independently of receptor sensitivity.

It is uncertain whether alterations responsible for the receptorindependent increase in contractility occur at the membrane level or at the level of the contractile machinery itself. Evidence for maturational change in membrane characteristics was present in the concentration-effect response to $\mathrm{KCl}$. Not only did the immature strips require a higher concentration of $\mathrm{KCl}$ to reach peak force generation, but also the threshold concentration of $\mathrm{KCl}$ required to initiate contraction was higher in the younger strips than in the adult. Inasmuch as $\mathrm{KCl}$-induced contractions are dependent on influx of extracellular $\mathrm{Ca}^{2+}(21)$, it is possible that the number or permeability of calcium channels increases with maturation. Such a developmental increase in calcium channel number has been identified in gastric smooth muscle (22). These authors speculated that the inability of immature smooth muscle to generate as much force as its mature counterpart was secondary to an inadequate number of channels present to promote rapid calcium influx.

Other investigators have identified changes in the quality or quantity of contractile proteins in smooth muscle cells of different developmental ages. Seidel et al. (16-18) have shown that the contractile protein/total protein content of vascular smooth muscle increases with age. How myosin content of airway smooth muscle changes with age is less clear. In studies using swine trachealis muscle, myosin content either increased from fetus to adult (23) or decreased from 2 to 10 wk postnatal age (24). Investigators have shown differences in myosin isoforms between embryonic, neonatal, and adult smooth muscle in both airway $(23-25)$ and nonairway smooth muscle $(26,27)$. Although any or all of these mechanisms may be responsible for the observed increase in force generation with age, the present study did not attempt to identify the causes of increased contractility.

Maturational studies of force generation in both vascular (16, 18) and gastrointestinal smooth muscle (9-11) demonstrate a trend similar to that of the present study; namely, that force generation increases with maturation. Evidence that airway smooth muscle from other species behaves similarly, however, is less clear. Studies in which force was not normalized demonstrate an increase in maximum force generation in rabbits (28) but a decrease in force generation to several agonists in maturing puppies (29). Tracheal spirals from young, middle-aged, and old guinea pigs demonstrated a decrease in force/dry weight ratio with advancing age (30). These authors speculated that one possible reason for this trend could be a maturational increase in the amount of noncontractile (cartilage) to contractile tissue present in their preparation. More recently, maturational changes in force generation and myosin content of porcine airway smooth muscle demonstrated an inverse relationship between age and airway smooth muscle contractility $(23,24)$ when the muscle was stimulated by cholinomimetic agents or by vagal stimulation. No differences in maximal force generation between 2- and 10wk-old swine were noted with $\mathrm{KCl}$ stimulation $(31,32)$, suggesting a difference between maturation of receptor-mediated and receptor-independent processes. Using the same preparation and species, however, Haxhiu-Poskurica et al. (33) showed no difference in maximal force generation to topically applied methacholine between 2- and 10-wk-old swine. Thus, species differences, alterations in response to different agonists, or differences in tissue preparation or normalization must all be considered when comparing maturational aspects of mammalian airway smooth muscle force generation.

Sensitivity to ACh increased with age, supporting the findings of other studies involving ovine airway smooth muscle $(34,35)$. In vitro studies in several other mammalian species, however, have shown a decline in sensitivity during postnatal development to histamine $(28,30,36)$, ACh (28), or $\alpha$-adrenergic agents (29). Thus, ovine airway smooth muscle may be unique regarding its maturational change in agonist sensitivity. Because in vivo studies of smooth muscle sensitivity rely on muscle shortening and resultant changes in lung mechanics, results may not be comparable to in vitro studies where isometric force is measured.

The present study demonstrates that airway smooth muscle from immature tracheae cannot generate as much force as adult 
trachealis can. The radius of the trachea from preterm lambs of 114-119 d gestation, however, is approximately half that of the adult (14). The LaPlace relationship, therefore, suggests that the preterm trachealis needs to generate a tension half that of the adult to withstand an equal deforming pressure. When immature airways are exposed to distending pressures associated with positive pressure ventilation, they become deformed, although adult airways do not (37). This pressure-induced injury to the immature airway may arise in part because of the inability of the preterm trachealis to generate enough tension to withstand that level of barotrauma. Both tracheomegaly (38) and tracheomalacia (39) have been described in preterm infants who required mechanical ventilation in the neonatal period. Thus, the limited ability of immature airway smooth muscle to generate tension may help explain why preterm neonates who require positive pressure ventilation are at risk for developing structural injury to the central airways.

Acknowledgments. The authors thank James P. Ryan, Ph.D., and Michael Wang, Ph.D., for their advice in the preparation of this manuscript.

\section{REFERENCES}

1. Burnard ED, Grattan-Smith P, Picton-Warlow CG, Grauaug A 1965 Pulmonary insufficiency in prematurity. Aust Paediatr $\mathrm{J} 1: 12-38$

2. Bhutani VK, Rubenstein SD, Shaffer TH 1981 Pressure-volume relationships of tracheae in fetal newborn and adult rabbits. Respir Physiol 43:221-231

3. Penn RB, Wolfson MR, Shaffer TH 1988 Effect of tracheal smooth muscle tone on collapsibility of immature airways. J Appl Physiol 65:863-869

4. Croteau JR, Cook CD 1961 Volume-pressure and length-tension measurements in human tracheobronchial segments. J Appl Physiol 16:170-172

5. Palombini B, Coburn RF 1972 Control of the compressibility of the canine trachea. Respir Physiol 15:365-383

6. Bhutani VK, Koslo RJ, Shaffer TH 1986 The effect of tracheal smooth muscle tone on neonatal airway collapsibility. Pediatr Res 20:492-495

7. Koslo RJ, Bhutani VK, Shaffer TH 1986 The role of tracheal smooth muscle contraction on neonatal tracheal mechanics. Pediatr Res 20:1216-1220

8. Panitch HB, Allen JL, Ryan JP, Wolfson MR, Shaffer TH 1989 A comparison of preterm and adult airway smooth muscle mechanics. J Appl Physiol 66:1760-1765

9. Zitterman J, Ryan JP 1990 Development of gastric antral smooth muscle contractility in newborn rabbits. Am J Physiol 258:G571-G575

10. Denehy CM, Ryan JP 1986 Development of gallbladder contractility in the guinea pig. Pediatr Res 20:214-217

11. Duckles SP, Banner Jr W 1984 Changes in vascular smooth muscle reactivity during development. Annu Rev Pharmacol Toxicol 24:65-83

12. Herlihy JT, Murphy RA 1973 Length-tension relationship of smooth muscle of the hog carotid artery. Circ Res 33:275-283

13. Humason GL 1979 Animal Tissue Techniques. WH Freeman, San Francisco

14. Deoras KS, Wolfson MR, Searls RL, Hilfer SR, Sheffield JB, Shaffer TH 1990 Use of a touch sensitive screen and computer assisted image analysis for quantitation of development changes in pulmonary structure. Pediatr Pulmonol 9:109-118

15. Carrino DA, Caplan AI 1986 Proteoglycan synthesis during skeletal muscle development. UCLA Symposia on Molecular and Cellular Biology, Vol 29,
Molecular Biology of Muscle Development. Alan R Liss, New York, pp 323-336

16. Seidel CL, Ross B, Michael L, Freedman J, Burdick B, Miller T 1987 Maturational changes in the pharmacological characteristics and actomyosin content of canine arterial and venous tissue Pediatr Res 21:152-158

17. Seidel CL, Murphy RA 1979 Changes in rat aortic actomyosin content with maturation. Blood Vessels 16:98-108

18. Seidel CL, Allen JC 1979 Pharmacologic characteristics and actomyosin content of aorta from neonatal rats. Am J Physiol 237:C81-C86

19. Moreno RH, Hogg JC, McLean TM, Pare PD 1987 Isovolumetric and isobaric rabbit tracheal contraction in vitro. J Appl Physiol 62:82-90

20. Penn RB, Wolfson MR, Shaffer TH 1989 Developmental differences in tracheal cartilage mechanics. Pediatr Res 26:429-433

21. Casteels R 1980 Electro- and pharmacomechanical coupling in vascular smooth muscle. Chest 78 (suppl): $150-155$

22. Hyman PE, Martin MG, Tomomasa T, Jing J, Snape Jr WJ 1989 Development of calcium channels in gastric smooth muscle. Pediatr Res 25:600-604

23. Sparrow MP, Mitchell HW 1990 Contraction of smooth muscle of pig airway tissues from before birth to maturity. J Appl Physiol 68:468-477

24. Murphy TM, Mitchell RW, Halayko A, Roach J, Roy L, Kelly EA, Munoz NM, Stephens NL, Leff AR 1991 Effect of maturational changes in myosin content and morphometry on airway smooth muscle contraction. Am J Physiol 260:L471-L480

25. Mohammad MA, Sparrow MP 1988 Changes in myosin heavy chain stoichiometry in pig tracheal smooth muscle during development. FEBS Lett 228:109-112

26. Kawamoto S, Adelstein RS 1987 Characterization of myosin heavy chains in cultured aorta smooth muscle cells. J Biol Chem 262:7282-7288

27. Masaki T, Takano-Ohmuro H, Suzuki R, Obinata T, Hamada Y, Mikawa T Tanaka T, Yoshikawa A, Katoch S 1986 Changes in the smooth muscle myosin isoforms during development of chicken gizzard. In: UCLA Symposia on Molecular and Cellular Biology, Vol 29, Molecular Biology of Muscle Development. Alan R Liss, New York, pp 323-336

28. Hayashi S, Toda N 1980 Age-related alterations in the response of rabbit tracheal smooth muscle to agents. J Pharmacol Exp Ther 214:675-681

29. Pandya KH 1977 Postnatal developmental changes in adrenergic receptor responses of the dog tracheal muscle. Arch Int Pharmacodyn 230:53-64

30. Brink C, Duncan PG, Midzenski M, Douglas JS 1980 Response and sensitivity of female guinea-pig respiratory tissues to agonists during ontogenesis. $J$ Pharmacol Exp Ther 215:426-433

31. Murphy TM, Mitchell RW, Blake JS, Mack MM, Kelly EA, Munoz NM, Leff AR 1989 Expression of airway contractile properties and acetycholinesterase activity in swine. J Appl Physiol 67:174-180

32. Mitchell RW, Murphy TM, Kelly E, Leff AR 1990 Maturation of acetylcholinesterase expression in tracheal smooth muscle contraction. Am $\mathrm{J}$ Physiol 259:L130-L135

33. Haxhiu-Poskurica B, Carlo WA, Miller MJ, DiFiore JM, Haxhiu MA, Martin RJ 1991 Maturation of respiratory reflex responses in the piglet. J Appl Physiol 70:608-616

34. Sauder RA, McNicol KJ, Stecenko AA 1986 Effect of age on lung mechanics and airway reactivity in lambs. J Appl Physiol 61:2074-2080

35. Stecenko A, McNicol K, Polk S 1989 Evaluation of the mechanism of decreased airway responsiveness in lambs. J Appl Physiol 66:727-731

36. Mitchell HW, Nayler RA 1986 Smooth muscle contractility and changes in histaminergic mechanisms in the pig trachea during development. Eur $\mathbf{J}$ Pharmacol 130:67-73

37. Bhutani VK, Rubenstein SD, Shaffer TH 1981 Pressure induced deformation in immature airways. Pediatr Res 15:829-832

38. Bhutani VK, Ritchie WG, Shaffer TH 1986 Acquired tracheomegaly in very preterm neonates. Am J Dis Child 140:449-452

39. Sotomayor JL, Godinex RI, Borden S, Wilmott RW 1986 Large-airway collapse due to acquired tracheobronchomalacia in infancy. Am J Dis Child 140:367371 